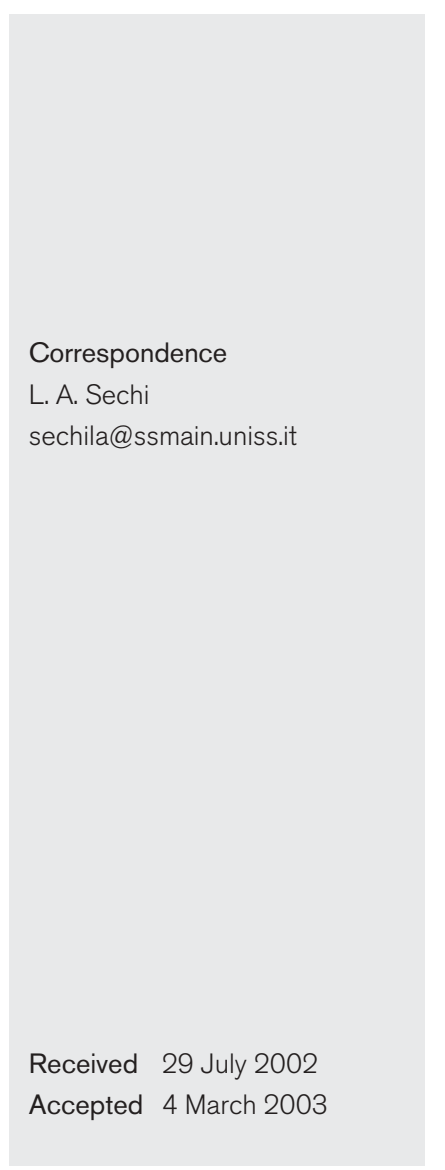

\title{
Incidence of virulence determinants in clinical Enterococcus faecium and Enterococcus faecalis isolates collected in Sardinia (Italy)
}

\author{
I. Duprè, ${ }^{1}$ S. Zanettii, ${ }^{1}$ A. M. Schito, ${ }^{2}$ G. Fadda ${ }^{3}$ and L. A. Sechi ${ }^{1}$ \\ ${ }^{1}$ Dipartimento di Scienze Biomediche, Sezione di Microbiologia Sperimentale e Clinica, Viale S. Pietro \\ 43/B, Università degli studi di Sassari, 07100 Sassari, Italy \\ ${ }^{2}$ Istituto di Microbiologia C. A. Romanzi, Università di Genova, Genoa, Italy \\ ${ }^{3}$ Istituto di Microbiologia, Università Cattolica del Sacro Cuore, Rome, Italy
}

\begin{abstract}
Enterococci are widely distributed in the environment; within the human body, they are normal commensals of the oral cavity, gastrointestinal tract and vagina. In recent years, enterococci have become one of the most frequent causes of acquired nosocomial infections worldwide. The molecular mechanism of virulence of these bacteria is still not completely understood. The aims of this work were to characterize phenotypically 47 isolates of Enterococcus faecalis and Enterococcus faecium collected in Sardinia (Italy) by their abilities to adhere to different epithelial cell lines (Vero and Caco-2 cells) and to associate their phenotypes with the presence of known virulence genes detected within their genomes by PCR. The following genes were amplified: AS (aggregation substance), esp (surface protein gene), ace (accessory colonization factor), efa $A$ (E. faecalis endocarditis antigen) and ge/E (gelatinase). The virulence genes were detected in E. faecalis isolates only, with the exception of esp, which was found in both species. The phenotypic and genotypic results were also compared with the susceptibility of isolates to various antibiotics.
\end{abstract}

\section{INTRODUCTION}

Enterococci are a component of the normal intestinal flora. In recent years, they have been reported as a major cause of nosocomial infections (Jett et al., 1994; Johnson, 1994), and they are among the most common pathogens isolated from infected surgical sites and blood-stream and urinary tract infections. Enterococcus faecalis is responsible for about $80-90 \%$ of all enterococcal infections and Enterococcus faecium accounts for most others (Jett et al., 1994; Johnson, 1994). An increasing number of strains are resistant to large numbers of antimicrobial agents and often cause fatal infections (Jett et al., 1994; Johnson, 1994; Willems et al., 2001). In Italy, the significance of enterococci as a cause of nosocomial infections is increasing but, fortunately, vancomycin-resistant enterococci are not as common as in other countries of Europe and the USA (Baldassarri et al., 2001; Sechi et al., 1998a).

The interaction between enterococci and different epithelial cells has been analysed previously (Chow et al., 1993; Kreft et al., 1992; Schlievert et al., 1998; Sußmuth et al., 2000; Wells et al., 2000). One of the aims of this work was to identify the role of the aggregation substance (AS) in the process of

Abbreviations: AS, aggregation substance; BAL, bronchoalveolar lavage. adhesion of enterococci to renal and intestinal epithelial cells in vitro (Chow et al., 1993; Kreft et al., 1992; Sußmuth et al., 2000). AS protein may be involved in virulence and is expressed on the surface of E. faecalis. The AS gene is present in pheromone-responsive plasmids (Sußmuth et al., 2000; Wells et al., 2000). AS facilitates aggregation of donor and recipient bacteria and helps in the transfer of conjugative plasmids (Chow et al., 1993). The role of other genes was also investigated. Recently, various studies have reported the presence of the esp gene in isolates of E. faecalis and E. faecium (Satake et al., 1997; Shankar et al., 1999, 2001; Woodford et al., 2001). Willems et al. (2001) reported a vancomycinresistant $E$. faecium subpopulation, genetically distinct from non-epidemic vancomycin-resistant E. faecium (VREF) isolates, which was responsible of hospital epidemics in the USA, Australia and Europe. This subpopulation contained a variant of the esp gene that was absent in all non-epidemic and animal isolates. Identification of the variant esp gene may be important in guiding infection-control strategies. Esp possesses a structure with multiple repeat motifs, characteristic of many surface proteins involved in the process of adhesion to eukaryotic cells (Shankar et al., 1999).

We analysed 47 E. faecalis and E. faecium isolates from clinical specimens such as urine and bronchoalveolar lavage (BAL) by detecting the virulence genes AS, gelE, ace, efa $A$ and 
esp by PCR and evaluating the ability of isolates to adhere to epithelial cell lines and to produce biofilms. The susceptibility of isolates to various antibiotics was also evaluated.

\section{METHODS}

Isolates. Forty-seven enterococcal isolates (15 E. faecalis and 32 E. faecium) were obtained from clinical samples taken from patients during 1998-2001 within different wards of the Hospital of Sassari (Sardinia, Italy). The $15 \mathrm{E}$. faecalis isolates were collected from vaginal swabs $(n=4)$, wound swabs $(n=3)$, BAL $(n=2)$, semen $(n=2)$, urinary devices $(n=2)$, pus $(n=1)$ and urine $(n=1)$. The 32 E. faecium isolates were collected from BAL $(n=17)$, pus $(n=4)$, perineum $(n=3)$, urine $(n=3)$, wound swabs $(n=2)$, catheter devices $(n=2)$ and heart devices $(n=1)$. All isolates were identified by the API ID32-Strep system (bioMérieux.)

DNA extraction and molecular typing. DNA was extracted as described previously (Sechi et al., 1998a, b). Molecular typing was performed as described previously (Sechi et al., 1998a).

Antibiotic susceptibility testing. Antibiotic susceptibility was assessed by using broth microdilution susceptibility tests to determine the MIC. Tests were performed in ready-to-use microtitre plates (Microdilution trays; Becton Dickinson) containing lyophilized antibiotics according to the manufacturer's instructions. The MICs and levels of resistance were determined according to the recommendations of the NCCLS (Dicuonzo et al., 2001). The antibiotics tested were penicillin, ampicillin, vancomycin, erythromycin, high-level gentamicin, teicoplanin, tetracycline, chloramphenicol and norfloxacin.

PCR for detection of vanA and vanB. PCRs were performed in a GeneAmp 2400 System thermal cycler (Applied Biosystems). The oligonucleotide primers for PCR amplifications were synthesized by Amersham Pharmacia Biotech. Primer sequences for vanA and vanB were those described by Satake et al. (1997). The reactions were performed in a total volume of $50 \mu \mathrm{l}$, using $5 \mu \mathrm{l}$ crude cell lysate, $40 \mathrm{pmol}$ of each of the four primers, $20 \mathrm{mM}$ Tris/ $\mathrm{HCl}$ (pH 8.4), $50 \mathrm{mM}$ $\mathrm{KCl}, 1.5 \mathrm{mM} \mathrm{MgCl}_{2}, 0.2 \mathrm{mM}$ each dNTP and $1.5 \mu \mathrm{l}$ AccuPrime Taq DNA polymerase (Invitrogen Life Technologies). Amplification condi- tions were as follows: an initial denaturation step of $94^{\circ} \mathrm{C}$ for $2 \mathrm{~min}, 30$ cycles of denaturation at $94{ }^{\circ} \mathrm{C}$ for $1 \mathrm{~min}$, annealing at $58^{\circ} \mathrm{C}$ for $1 \mathrm{~min}$ and extension at $72{ }^{\circ} \mathrm{C}$ for $1 \mathrm{~min}$, followed by a final elongation at $72{ }^{\circ} \mathrm{C}$ for $10 \mathrm{~min}$. The PCR products were analysed on $1.2 \%$ agarose gels stained with ethidium bromide solution and visualized under UV light. The clinical isolates E. faecalis A256 and E. faecalis Mn1, respectively used as positive controls for vanA and $\operatorname{van} B$ resistance, were kindly provided by P. S. Cocconcelli (Università Cattolica del Sacro Cuore, Piacenza, Italy).

Detection of virulence genes by PCR. Primers and PCR conditions are given in Table 1. With the exception of primers for esp (Shankar et al., 1999), primers were designed in this study.

Restriction digestion of esp amplified products. Amplified products from $e s p$ were digested with HindIII according to the supplier's instructions (New England Biolabs).

Adhesion experiments. Caco-2 and Vero cell lines were obtained from the American Type Culture Collection (Manassas, VA, USA) and were cultivated in 24-well plastic dishes. Briefly, Caco-2 cells and Vero cells were cultivated in Dulbecco's modified Eagle's medium supplemented with $15 \%$ fetal bovine serum and $4 \mathrm{mM}$ L-glutamine. All tissueculture reagents were obtained from Sigma. Cells were seeded at $2 \times 10^{4}$ (Caco-2) or $2 \times 10^{3}$ (Vero) cells per well and incubated at $37^{\circ} \mathrm{C}$ in $9.5 \%$ $\mathrm{CO}_{2}$. Cells were used when they were semiconfluent. Cultures of $E$. faecalis and E. faecium were grown overnight in brain heart infusion (BHI) broth and diluted in the medium used for incubation of the cell lines. One millilitre, containing $10^{6}$ bacteria, was added to each well containing Caco-2 or Vero cells. Adhesion was estimated by counting the number of adhered bacteria per cell after incubation for $2 \mathrm{~h}$ at $37^{\circ} \mathrm{C}$ and staining with May-Grunwald-Giemsa stain as described previously (Zanetti et al., 1992).

Biofilm assay. The ability of the enterococcal isolates to form a biofilm on an abiotic surface was quantified as described by Toledo-Arana et al. (2001). Isolates were grown overnight at $37^{\circ} \mathrm{C}$ in $\mathrm{BHI}$ broth plus $0 \cdot 25 \%$ glucose. The culture was diluted $1: 20$ in fresh BHI broth plus $0.25 \%$ glucose at $37^{\circ} \mathrm{C}$ and $200 \mu \mathrm{l}$ of this suspension was used to inoculate sterile 96 -well polystyrene microtitre plates (Iwaki). After $24 \mathrm{~h}$ at $37^{\circ} \mathrm{C}$, wells were washed with PBS, dried in an inverted position and stained

\section{Table 1. PCR primers and reaction conditions}

All PCR programs consisted of 30 cycles of denaturation at $94{ }^{\circ} \mathrm{C}$ for $1 \mathrm{~min}$, annealing for $1 \mathrm{~min}$ at the temperature shown and elongation at $72{ }^{\circ} \mathrm{C}$ for $1 \mathrm{~min}$.

\begin{tabular}{|c|c|c|c|c|}
\hline Target & Primer & Sequence $\left(5^{\prime}-3^{\prime}\right)$ & $\begin{array}{c}\text { Product length } \\
\text { (bp) }\end{array}$ & $\begin{array}{c}\text { Annealing } \\
\text { temperature } \\
\left({ }^{\circ} \mathrm{C}\right)\end{array}$ \\
\hline \multirow[t]{2}{*}{ ace } & ACE1 & AAAGTAGAATTAGATCCACAC & 320 & 56 \\
\hline & ACE2 & TCTATCACATTCGGTTGCG & & \\
\hline \multirow[t]{2}{*}{ gelE } & gelE1 & AGTTCATGTCTATTTTCTTCAC & 402 & 56 \\
\hline & gelE2 & CTTCATTATTTACACGTTTG & & \\
\hline \multirow[t]{2}{*}{$e f a A$} & efaAl & CGTGAGAAAGAAATGGAGGA & 499 & 56 \\
\hline & efaA2 & CTACTAACACGTCACGAATG & & \\
\hline \multirow[t]{2}{*}{ AS } & AS1 & CCAGTAATCAGTCCAGAAACAACC & 406 & 54 \\
\hline & AS2 & TAGCTTTTTTCATTCTTGTGTTTGTT & & \\
\hline \multirow[t]{2}{*}{ esp } & esp46 & TTACCAAGATGGTTCTGTAGGCAC & A repeats ${ }^{*}$ & 58 \\
\hline & esp47 & CCAAGTATACTTAGCATCTTTTGG & & \\
\hline
\end{tabular}

*Primers esp46/esp47 (Shankar et al., 1999) are specific for amplification of the A repeats. 
with $1 \%$ crystal violet for $15 \mathrm{~min}$. The wells were rinsed once more and the crystal violet was solubilized in $200 \mu \mathrm{l}$ ethanol/acetone $(80: 20, \mathrm{v} / \mathrm{v})$. The $A_{595}$ was determined using a microplate reader (Multiskan EC; LabSystems). Biofilm formation was scored as follows: - , nonbiofilm-forming $\left(A_{595} \leqslant 1\right)$; + , weak $\left(1<A_{595} \leqslant 2\right)$; ++ , moderate $\left(2<A_{595} \leqslant 3\right) ;+++$, strong $\left(A_{595}>3\right)$. Each assay was performed in triplicate and repeated three times.

\section{RESULTS}

The isolates of E. faecium and E. faecalis were evaluated for their antibiotic susceptibility (Table 2). All the E. faecium isolates exhibited resistance to a range of antibiotic substances. The highest percentages of resistant isolates were observed in the presence of penicillin, erythromycin and ampicillin (Table 2). A large number of isolates exhibited resistance to high levels of aminoglycosides, which predicts a lack of synergy between cell-wall-active agents (ampicillin, penicillin and vancomycin) and aminoglycosides. Only three clinical isolates $(10 \%)$ were resistant to vancomycin, with MICs greater than $32 \mu \mathrm{g} \mathrm{ml}^{-1}$. All the other isolates were susceptible. Vancomycin and teicoplanin seemed to be the most effective antimicrobials, with about $90 \%$ of isolates susceptible.

A large proportion of the E. faecalis isolates were resistant to tetracycline (73\%), as well as to penicillin (60\%) (Table 2). More than $30 \%$ of the isolates were resistant to chloramphenicol. All E. faecalis isolates were susceptible or showed intermediate susceptibility to ampicillin, vancomycin and teicoplanin (Table 2).

To determine whether the isolates were clonal, all isolates were typed by ribotyping, as described previously (Sechi et al., 1998a). Among the $32 \mathrm{E}$. faecium isolates analysed, 26 different ribotyping patterns were identified, whereas the 15 E. faecalis isolates generated 14 different ribotyping patterns (data not shown).

All isolates were screened for the presence of virulence genes identified previously in E. faecalis and E. faecium using primers designed in-house or published previously (Table 1). Nine E. faecalis isolates $(60 \%)$ were positive for ace, 13 $(86.6 \%)$ for $e f a A, 11(73.3 \%)$ for gelE, $5(33.3 \%)$ for AS and $9(60 \%)$ for $\operatorname{esp}$ (Table 3 ). Of the 32 E. faecium isolates, none yielded a product with the ace, efaA, AS or gelE primers. However, 23 isolates $(71.9 \%)$ generated the expected product when esp primers were used (Table 3 ).

When the E. faecalis isolates were analysed, primers targeting ace, efaA, gelE and AS generated bands of the expected sizes, whereas the esp primers generated bands of different sizes, as reported previously (Shankar et al., 1999), although not all of them were multiples of $252 \mathrm{bp}$ (Shankar et al., 1999). On the basis of the numbers of bands and their molecular sizes, three patterns were identified for E. faecalis isolates and four patterns were identified for the E. faecium isolates (Fig. 1a). Amplification of esp from $E$. faecalis produced smaller bands in comparison with the bands generated from $E$. faecium (Fig. 1a). In order to verify that the variation in size was due to the presence of different numbers of A repeats, the amplified bands were digested with HindIII (which cuts once within each A repeat unit) and the digestion products were visualized after electrophoresis on a $2 \%$ agarose gel (Fig. 1b). In all cases, three major bands (of 173, 252 and 261 bp) of the expected size were obtained (Fig. 1b), as reported previously (Wells et al., 2000). The number of A repeats varied from two (E. faecalis isolates) to six among most of the E. faecium isolates (Fig. 1a).

All 47 isolates were tested for their ability to adhere to renal (Vero) and intestinal (Caco-2) epithelial cells (Table 3). Both E. faecalis and E. faecium isolates adhered to Vero cells; however, some E. faecalis isolates (e.g. isolate 2) were highly adhesive, with more than 30 bacteria per cell (after examining more than 40 fields per sample containing at least 20 epithelial cells, each sample was done in triplicate). All $E$. faecalis isolates were more adhesive to Vero cells than to Caco-2 cells.

Various E. faecium isolates were adhesive to Vero cells, whereas only two isolates were found on Caco-2 cells (Table 3). To investigate a possible correlation between the presence of the esp gene and the capacity to adhere to epithelial cells and/or the capacity of the isolates to form biofilms, the capacity of the 47 enterococcal isolates to form biofilms on polystyrene microtitre plates was evaluated. The capacity for biofilm formation was scored as non-biofilm-forming, weak, moderate or strong as described in Methods (Satake et al., 1997). In contrast to a previous study (Eaton \& Gasson, 2001), the presence of the esp gene was not clearly associated with the capacity for biofilm formation (Table 3 ).

\section{DISCUSSION}

Enterococci are important nosocomial pathogens and are one of the major causes of infection within hospitals. The ability to acquire genes encoding antibiotic resistance combined with a natural resistance to various antimicrobial agents and to extreme environments (such as low $\mathrm{pH}$, high salinity and high temperatures) makes these bacteria exceptional survivors (Jett et al., 1994; Johnson, 1994). Many of the E. faecium isolates tested were resistant to a wide range of antibiotics, such as penicillin, ampicillin and erythromycin; they were also resistant to aminoglycosides at a high level, from which one can predict that there is resistance to synergism between cell-wall-active agents (ampicillin, penicillin, vancomycin) and aminoglycosides. This is a serious problem, as it reduces the number of possible treatments available for enterococcal infections. A combination of penicillin or ampicillin plus an aminoglycoside is usually indicated for serious enterococcal infections, such as endocarditis. The high percentage $(75 \%)$ of clinical isolates resistant to ampicillin found in this study is alarming, as ampicillin is often the preferred treatment for enterococcal infections. Only three E. faecium clinical isolates (10\%) were resistant to vancomycin, with MICs greater than $32 \mu \mathrm{g} \mathrm{m}^{-1}$. All the other isolates were susceptible. Moreover, the three vancomycin-resistant isolates were also multidrug-resistant, and this is of concern, as this resistance may be transferred to 
Table 2. Antibiotic resistance of $E$. faecalis and $E$. faecium isolates

Results were interpreted on the basis of MICs for enterococci according to Dicuonzo et al. (2001) and are scored as: S, susceptible; I, intermediate; R, resistant. VAN, Vancomycin; TEC, teicoplanin; AMP, ampicillin; PEN, penicillin; EM, erythromycin; TC, tetracycline; CL, chloramphenicol; NX, norfloxacin; GM, gentamicin.

\begin{tabular}{|c|c|c|c|c|c|c|c|c|c|}
\hline Isolate & VAN & TEC & AMP & PEN & EM & TC & CL & NX & GM \\
\hline \multicolumn{10}{|c|}{ E. faecalis } \\
\hline 1 & I & I & S & $\mathrm{R}$ & I & $\mathrm{R}$ & I & S & $\mathrm{S}$ \\
\hline 2 & S & S & S & I & $\mathrm{R}$ & $\mathrm{R}$ & $\mathrm{R}$ & S & $\mathrm{S}$ \\
\hline 3 & S & S & S & I & $\mathrm{R}$ & $\mathrm{R}$ & $\mathrm{R}$ & $\mathrm{S}$ & $\mathrm{R}$ \\
\hline 4 & S & S & S & I & $\mathrm{R}$ & $\mathrm{R}$ & $\mathrm{R}$ & S & $\mathrm{R}$ \\
\hline 5 & I & S & S & $\mathrm{R}$ & I & $\mathrm{R}$ & $S$ & $S$ & $\mathrm{~S}$ \\
\hline 6 & S & S & $S$ & I & I & $\mathrm{R}$ & $\mathrm{R}$ & $S$ & $\mathrm{R}$ \\
\hline 7 & S & S & S & $\mathrm{R}$ & I & $\mathrm{R}$ & $S$ & $\mathrm{R}$ & $\mathrm{R}$ \\
\hline 8 & S & S & S & $\mathrm{S}$ & I & $S$ & S & I & $\mathrm{S}$ \\
\hline 9 & S & S & S & $\mathrm{R}$ & I & $\mathrm{R}$ & S & $\mathrm{S}$ & $\mathrm{S}$ \\
\hline 10 & I & S & S & $\mathrm{R}$ & I & $\mathrm{R}$ & S & S & $\mathrm{S}$ \\
\hline 11 & S & S & S & $\mathrm{R}$ & I & $S$ & I & I & $\mathrm{S}$ \\
\hline 12 & I & S & S & $\mathrm{R}$ & I & $S$ & S & I & $\mathrm{S}$ \\
\hline 13 & S & S & S & I & I & I & S & $\mathrm{S}$ & $\mathrm{S}$ \\
\hline 14 & S & I & S & $\mathrm{R}$ & I & $\mathrm{R}$ & S & $\mathrm{R}$ & $\mathrm{R}$ \\
\hline 15 & I & $S$ & $S$ & $\mathrm{R}$ & $\mathrm{R}$ & $\mathrm{R}$ & $\mathrm{R}$ & $S$ & $S$ \\
\hline \multicolumn{10}{|c|}{ E. faecium } \\
\hline 1 & $\mathrm{R}$ & $\mathrm{R}$ & S & $\mathrm{R}$ & $\mathrm{R}$ & $\mathrm{R}$ & I & $\mathrm{R}$ & $\mathrm{R}$ \\
\hline 2 & $\mathrm{R}$ & $\mathrm{R}$ & $\mathrm{R}$ & $\mathrm{R}$ & $\mathrm{R}$ & $\mathrm{R}$ & $\mathrm{R}$ & $\mathrm{R}$ & $\mathrm{R}$ \\
\hline 3 & $\mathrm{R}$ & $\mathrm{R}$ & S & S & $\mathrm{S}$ & $S$ & S & $\mathrm{R}$ & $\mathrm{S}$ \\
\hline 4 & $S$ & S & $\mathrm{R}$ & $\mathrm{R}$ & $\mathrm{R}$ & $S$ & S & $\mathrm{R}$ & $\mathrm{R}$ \\
\hline 5 & S & S & $\mathrm{R}$ & $\mathrm{R}$ & $\mathrm{R}$ & $S$ & S & $\mathrm{R}$ & $\mathrm{R}$ \\
\hline 6 & S & I & S & $\mathrm{R}$ & $\mathrm{R}$ & $\mathrm{R}$ & S & $\mathrm{R}$ & $\mathrm{R}$ \\
\hline 7 & S & S & $\mathrm{R}$ & $\mathrm{R}$ & $\mathrm{R}$ & $\mathrm{R}$ & S & $\mathrm{S}$ & $\mathrm{S}$ \\
\hline 8 & S & S & $\mathrm{R}$ & I & I & I & I & I & I \\
\hline 9 & S & S & S & $\mathrm{R}$ & S & $\mathrm{S}$ & S & $\mathrm{R}$ & $\mathrm{S}$ \\
\hline 10 & S & S & $\mathrm{R}$ & $\mathrm{R}$ & $\mathrm{R}$ & $S$ & S & I & $S$ \\
\hline 11 & S & S & $\mathrm{R}$ & $\mathrm{R}$ & $\mathrm{R}$ & $S$ & I & I & $\mathrm{R}$ \\
\hline 12 & $S$ & S & $\mathrm{R}$ & $\mathrm{R}$ & $\mathrm{R}$ & $S$ & I & I & $S$ \\
\hline 13 & S & S & $\mathrm{R}$ & $\mathrm{R}$ & $\mathrm{R}$ & $\mathrm{S}$ & $\mathrm{R}$ & I & $\mathrm{S}$ \\
\hline 14 & S & S & $\mathrm{R}$ & $\mathrm{R}$ & $\mathrm{R}$ & I & S & $\mathrm{R}$ & $\mathrm{R}$ \\
\hline 15 & S & S & $\mathrm{R}$ & $\mathrm{R}$ & $\mathrm{R}$ & $\mathrm{R}$ & I & I & $S$ \\
\hline 16 & S & S & $\mathrm{R}$ & $\mathrm{R}$ & $\mathrm{R}$ & $\mathrm{R}$ & S & I & $\mathrm{S}$ \\
\hline 17 & S & I & $\mathrm{R}$ & $\mathrm{R}$ & $\mathrm{R}$ & $\mathrm{S}$ & I & $\mathrm{R}$ & $\mathrm{R}$ \\
\hline 18 & S & S & S & $\mathrm{R}$ & I & $\mathrm{R}$ & I & I & $\mathrm{S}$ \\
\hline 19 & S & S & $\mathrm{R}$ & $\mathrm{R}$ & $\mathrm{R}$ & $\mathrm{S}$ & S & $\mathrm{R}$ & $\mathrm{S}$ \\
\hline 20 & S & S & S & $S$ & $\mathrm{R}$ & $\mathrm{S}$ & I & $\mathrm{S}$ & $\mathrm{S}$ \\
\hline 21 & S & S & $\mathrm{R}$ & $\mathrm{R}$ & $\mathrm{R}$ & $S$ & $S$ & $\mathrm{R}$ & $\mathrm{S}$ \\
\hline 106 & S & S & $\mathrm{R}$ & $\mathrm{R}$ & $\mathrm{R}$ & $\mathrm{R}$ & S & $\mathrm{R}$ & $\mathrm{S}$ \\
\hline 109 & S & $S$ & $S$ & $\mathrm{R}$ & $\mathrm{R}$ & $\mathrm{R}$ & I & $\mathrm{R}$ & $\mathrm{S}$ \\
\hline 111 & S & I & $\mathrm{R}$ & $\mathrm{R}$ & $\mathrm{R}$ & $\mathrm{S}$ & I & I & I \\
\hline 113 & S & I & $\mathrm{R}$ & $\mathrm{R}$ & $\mathrm{R}$ & S & S & I & I \\
\hline 114 & S & S & $\mathrm{R}$ & $\mathrm{R}$ & $\mathrm{R}$ & $\mathrm{S}$ & I & $\mathrm{R}$ & $\mathrm{S}$ \\
\hline 116 & S & I & $\mathrm{R}$ & $\mathrm{R}$ & $\mathrm{R}$ & $S$ & $\mathrm{R}$ & I & $\mathrm{R}$ \\
\hline 118 & $S$ & I & $\mathrm{R}$ & $\mathrm{R}$ & $\mathrm{R}$ & $\mathrm{R}$ & S & $\mathrm{R}$ & $\mathrm{R}$ \\
\hline 119 & S & S & S & $\mathrm{R}$ & $\mathrm{R}$ & $\mathrm{S}$ & $\mathrm{R}$ & I & $\mathrm{S}$ \\
\hline 120 & S & $S$ & $\mathrm{R}$ & $\mathrm{R}$ & $\mathrm{R}$ & $\mathrm{R}$ & $\mathrm{R}$ & $\mathrm{S}$ & $\mathrm{S}$ \\
\hline 121 & S & $S$ & $S$ & S & $\mathrm{R}$ & $S$ & S & S & $\mathrm{S}$ \\
\hline 122 & S & I & $\mathrm{R}$ & $\mathrm{R}$ & $\mathrm{R}$ & $\mathrm{R}$ & $\mathrm{R}$ & I & $\mathrm{S}$ \\
\hline
\end{tabular}


Table 3. Distribution of phenotypic and genotypic virulence determinants among $E$. faecalis and E. faecium isolates

Adhesion is scored as: - , non-adherent; + , weak ( $<1$ bacterium per cell); ++ , moderate ( $~ 5$ bacteria per cell); +++ , strong $(>10$ bacteria per cell). Biofilm formation is scored as absent $(-)$, weak $(+)$, moderate $(++)$ or strong $(+++)$ as described in Methods.

\begin{tabular}{|c|c|c|c|c|c|c|c|c|c|}
\hline \multirow[t]{2}{*}{ Isolate } & \multirow[t]{2}{*}{ Source } & \multicolumn{5}{|c|}{ Detection by PCR } & \multicolumn{2}{|c|}{ Adhesion } & \multirow[t]{2}{*}{ Biofilm production } \\
\hline & & ace & $e f a A$ & gelE & AS & esp & Vero & Caco-2 & \\
\hline \multicolumn{10}{|l|}{ E. faecalis } \\
\hline 1 & Wound swab & + & + & + & - & + & - & - & ++ \\
\hline 2 & Vaginal swab & + & + & - & + & + & +++ & - & ++ \\
\hline 3 & Urine & - & + & - & + & + & - & - & +++ \\
\hline 4 & Urinary device & - & + & + & - & + & - & - & ++ \\
\hline 5 & Nail swab & + & + & + & - & - & +++ & + & + \\
\hline 6 & Wound swab & - & + & + & - & + & - & - & - \\
\hline 7 & Pus & + & - & + & + & + & + & + & + \\
\hline 8 & Sputum & - & - & + & - & - & - & - & + \\
\hline 9 & Urinary device & + & + & + & - & - & + & - & + \\
\hline 10 & Vaginal swab & + & + & - & - & - & ++ & + & ++ \\
\hline 11 & Semen & + & + & + & - & + & ++ & + & + \\
\hline 12 & Vaginal swab & + & + & + & - & - & + & - & + \\
\hline 13 & Semen & - & + & - & + & + & +++ & + & ++ \\
\hline 14 & BAL & - & + & + & - & - & + & - & - \\
\hline 15 & Vaginal swab & + & + & + & + & + & ++ & + & ++ \\
\hline Positive $[n(\%)]$ & & $9(60)$ & $13(86 \cdot 6)$ & $11(73 \cdot 3)$ & $5(33 \cdot 3)$ & $9(60)$ & & & \\
\hline \multicolumn{10}{|l|}{ E. faecium } \\
\hline 1 & BAL & - & - & - & - & + & - & - & - \\
\hline 2 & BAL & - & - & - & - & + & - & - & - \\
\hline 3 & BAL & - & - & - & - & - & - & - & - \\
\hline 4 & Pus & - & - & - & - & + & - & - & - \\
\hline 5 & Perineum & - & - & - & - & - & - & - & - \\
\hline 6 & BAL & - & - & - & - & - & - & - & - \\
\hline 7 & BAL & - & - & - & - & + & - & + & - \\
\hline 8 & BAL & - & - & - & - & + & - & - & - \\
\hline 9 & BAL & - & - & - & - & + & - & - & - \\
\hline 10 & BAL & - & - & - & - & + & - & - & - \\
\hline 11 & BAL & - & - & - & - & + & - & - & - \\
\hline 12 & BAL & - & - & - & - & + & - & - & - \\
\hline 13 & BAL & - & - & - & - & + & - & - & + \\
\hline 14 & BAL & - & - & - & - & + & - & - & - \\
\hline 15 & BAL & - & - & - & - & + & - & - & + \\
\hline 16 & Pus & - & - & - & - & + & - & - & - \\
\hline 17 & Heart device & - & - & - & - & + & - & - & - \\
\hline 18 & Pus & - & - & - & - & - & - & - & - \\
\hline 19 & Wound swab & - & - & - & - & + & - & - & + \\
\hline 20 & Perineum & - & - & - & - & + & - & - & + \\
\hline 21 & Perineum & - & - & - & - & + & - & - & - \\
\hline 106 & BAL & - & - & - & - & - & + & + & + \\
\hline 109 & Pus & - & - & - & - & - & - & - & - \\
\hline 111 & Urine & - & - & - & - & + & + & - & - \\
\hline 113 & Urine & - & - & - & - & + & + & - & - \\
\hline 114 & Urinary device & - & - & - & - & + & + & - & - \\
\hline 116 & Urinary device & - & - & - & - & + & - & - & - \\
\hline 118 & BAL & - & - & - & - & + & - & - & - \\
\hline 119 & Wound swab & - & - & - & - & - & - & - & - \\
\hline 120 & BAL & - & - & - & - & - & - & - & - \\
\hline 121 & BAL & - & - & - & - & - & + & + & - \\
\hline 122 & Urine & - & - & - & - & + & + & - & - \\
\hline Positive $[n(\%)]$ & & 0 & 0 & 0 & 0 & $23(71.9)$ & & & \\
\hline
\end{tabular}


(a)

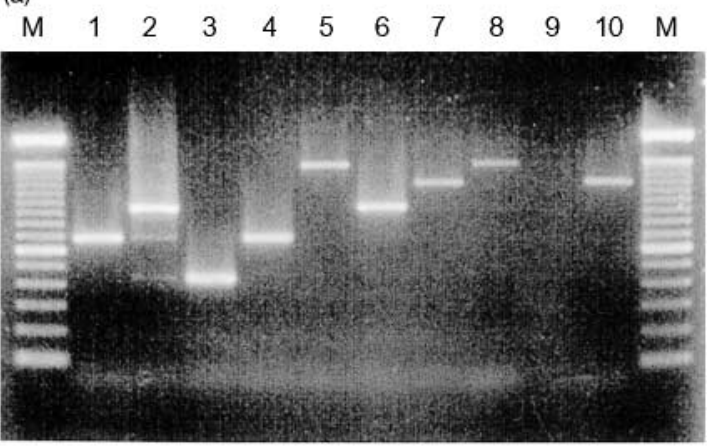

(b)

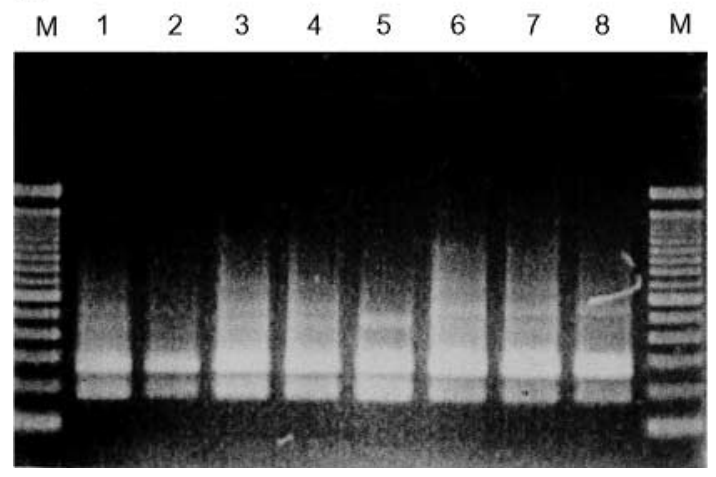

Fig. 1. Agarose gel electrophoresis of esp amplification products from E. faecalis and E. faecium isolates (a) and Hindlll-digests of the esp PCR products (b). (a) Lanes: M, 100 bp ladder; 1-4, E. faecalis isolates 1 (lane 1), $3(2), 11$ (3) and 13 (4); 5- 10, E. faecium isolates 1 (5), 8 (6), 10 (7), 14 (8), 106 (9) and 114 (10). (b) Lanes: M, 100 bp ladder; 1-4, E. faecalis isolates 1 (lane 1), 11 (2), 3 (3) and 13 (4); 58, E. faecium isolates 1 (5), 8 (6), 10 (7) and 14 (8).

more pathogenic micro-organisms. They were also resistant to high levels of aminoglycosides, with only one of them susceptible to penicillin. This means that the possible antimicrobial therapies for infections associated with such enterococcal strains are limited. Nonetheless, it is worth noting that the percentage of vancomycin-resistant enterococci isolated in the present investigation from human samples collected in Sardinian hospitals was very low, when compared with data reported from other countries.

Only three isolates from clinical samples gave the expected amplification product of $1030 \mathrm{bp}$ when amplified with primers specific for vanA. These were the same isolates that were resistant to vancomycin and teicoplanin in antibioticsusceptibility tests. No vanB genes were detected. The good fit between the phenotypic and genetic tests indicates that all the vanA genes present in the genomes of these isolates are actually expressed as acquired vancomycin resistance.

The 15 E. faecalis isolates showed elevated resistance to penicillin but not ampicillin, erythromycin or tetracycline; a small number of isolates were also resistant to gentamicin. None of the isolates was resistant to vancomycin or teicoplanin.
Enterococci are opportunistic pathogens and the immune system of the host is an important factor in the development of disease. Little is known about the mechanism of virulence of these bacteria and genes involved in the pathogenesis of disease have only recently been identified. E. faecalis is responsible for $80-90 \%$ of all infections due to enterococci, and $E$. faecium is responsible for most of the remainder. $E$. faecalis and E. faecium show great differences in the incidence of virulence determinants (Toledo-Arana et al., 2001; Zanetti et al., 1992). On the basis of sequences of virulence genes available in the literature (Coque et al., 1995; Eaton \& Gasson, 2001; Ike et al., 1987; Lowe et al., 1995; Nallapareddy et al., 2000; Schlievert et al., 1998; Shankar et al., 1999; Singh et al., 1998; Su et al., 1991), 47 clinical enterococcal isolates from patients of the Sassari Hospital in Sardinia (Italy) (15E. faecalis and 32 E. faecium) were characterized genotypically, and their adhesion properties on Vero and Caco-2 epithelial cells and their capacity to produce biofilms were tested. Ribotyping confirmed that the isolates were not clonal.

The virulence determinants were present in different proportions of isolates of the two species. The E. faecalis isolates tested carried multiple virulence genes, whereas the $E$. faecium isolates tested were devoid of these virulence genes, except for esp. The results obtained for esp are different from the first report of Shankar et al. (1999). We found $71.9 \%$ of $E$. faecium isolates positive for esp, whereas only $60 \%$ of $E$. faecalis isolates yielded a PCR product. Other authors (Eaton \& Gasson, 2001; Willems et al., 2001; Woodford et al., 2001) have reported similar prevalence of esp in E. faecium isolates from medical environments; esp was detected in $63-78 \%$ of clinical isolates in the UK (Willems et al., 2001; Woodford et al., 2001). The large number of clinical E. faecium isolates positive for esp suggests a role in pathogenicity. Moreover, Shankar et al. (2001) suggest that Esp contributes to colonization and persistence of E. faecalis within the urinary tract. The esp primers used in this study amplify the A repeated region of the esp gene; our results show that larger numbers of A repeats were present within the E. faecium isolates tested (four different patterns generated) in comparison with three patterns found in E. faecalis isolates. To verify that variation occurred in the number of A repeats, the amplification products were digested with HindIII (which cuts once within each A repeat). The digestion confirmed our hypothesis; a similar observation has been reported for $E$. faecalis (Shankar et al., 1999), where addition or deletion of esp repeat units led to changes in the size of the encoded protein. It was thought that Esp size variation at the cell surface could define an environment-specific function for Esp. Our results indicate no correlation between the epithelial cell-adhesion phenotype and the presence of esp for either E. faecalis or E. faecium.

Toledo-Arana et al. (2001) reported high sequence similarity between Esp and Bap (a biofilm-associated protein of Staphylococcus aureus); for this reason, the association of esp with the capacity to form biofilms on a polystyrene surface was investigated. A strong association between the presence of esp and biofilm formation in E. faecalis has been 
reported (Toledo-Arana et al., 2001). In the same study, it was suggested that the presence of esp rather than the phenotype (adherence or biofilm formation) is a good marker for identification of strains that are highly adherent to abiotic surfaces. Our results confirm this association for $E$. faecalis but not for the E. faecium isolates tested. For the $E$. faecium isolates, an association was found between the presence of $e s p$ and the capacity to grow in the presence of ampicillin. Of the nine esp-negative E. faecium isolates, six were susceptible to ampicillin, whereas, of the 23 esp-positive isolates, only three were susceptible to ampicillin.

The ace gene, previously reported to mediate adherence to collagen types I and IV and laminin (Nallapareddy et al., 2000), was detected in nine of 15 E. faecalis isolates, but no amplification was obtained from the E. faecium isolates studied.

Enterococcus species have an efficient gene-transfer mechanism, including conjugation via the sex-pheromone plasmids and conjugative transposon. The chance that virulence factors may be acquired by conjugation is very high, as reported previously (Chow et al., 1993; Coque et al., 1995; Heaton et al., 1996; Jett et al., 1994). The adhesion experiments clearly confirmed that $E$. faecalis is more virulent than E. faecium, but none of the genes tested was always associated with the virulence phenotype. In particular, a large number of $E$. faecalis isolates were adhesive on Vero cells, whereas adhesion on Caco-2 cells was less evident and was observed in only few isolates. Bacterial adherence was not associated significantly with any of the virulence factors studied, in agreement with the observations of other authors (Archimbaud et al., 2002).

In conclusion, our results confirm the presence of various virulence genes in clinical $E$. faecalis isolates and the absence of the same genes in E. faecium isolates, with the exception of esp. We observed that the E. faecium isolates analysed are enriched in esp, a phenomenon that has been described previously for E. faecalis (Shankar et al., 1999) and only recently for E. faecium of nosocomial origin (Eaton \& Gasson, 2001; Willems et al., 2001; Woodford et al., 2001), but we were not able to correlate the presence of esp with the capacity to form biofilms or to adhere to epithelial cells. Further studies are necessary in order to analyse the association and role of virulence genes in the pathogenicity of $E$. faecium.

\section{REFERENCES}

Archimbaud, C., Shankar, N., Forestier, C., Baghdayan, A., Gilmore, M. S., Charbonne, F. \& Joly, B. (2002). In vitro adhesive properties and virulence factors of Enterococcus faecalis strains. Res Microbiol 153, $75-80$.

Baldassarri, L., Bertuccini, L., Ammendolia, M. G., Gherardi, G. \& Creti, R. (2001). Variant esp gene in vancomycin-sensitive Enterococcus faecium. Lancet 357, 1802.

Chow, J. W., Thal, L. A., Perri, M. B., Vazquez, J. A., Donabedian, S. M., Clewell, D. B. \& Zervos, M. J. (1993). Plasmid-associated hemolysin and aggregation substance production contribute to virulence in experimental enterococcal endocarditis. Antimicrob Agents Chemother 37, 2474-2477.

Coque, T. M., Patterson, J. E., Steckelberg, J. M. \& Murray, B. E. (1995). Incidence of hemolysin, gelatinase, and aggregation substance among enterococci isolated from patients with endocarditis and other infections and from feces of hospitalized and community-based persons. J Infect Dis 171, 1223-1229.

Dicuonzo, G., Gherardi, G., Lorino, G. \& 7 other authors (2001). Antibiotic resistance and genotypic characterization by PFGE of clinical and environmental isolates of enterococci. FEMS Microbiol Lett 201, 205-211.

Eaton, T. J. \& Gasson, M. J. (2001). Molecular screening of Enterococcus virulence determinants and potential for genetic exchange between food and medical isolates. Appl Environ Microbiol 67, 1628-1635.

Heaton, M. P., Discotto, L. F., Pucci, M. J. \& Handwerger, S. (1996). Mobilization of vancomycin resistance by transposon-mediated fusion of a VanA plasmid with an Enterococcus faecium sex pheromoneresponse plasmid. Gene 171, 9-17.

Ike, Y., Hashimoto, H. \& Clewell, D. B. (1987). High incidence of hemolysin production by Enterococcus (Streptococcus) faecalis strains associated with human parenteral infections. J Clin Microbiol 25, 1524-1528.

Jett, B. D., Huycke, M. M. \& Gilmore, M. S. (1994). Virulence of enterococci. Clin Microbiol Rev 7, 462-478.

Johnson, A. P. (1994). The pathogenicity of enterococci. J Antimicrob Chemother 33, 1083-1089.

Kreft, B., Marre, R., Schramm, U. \& Wirth, R. (1992). Aggregation substance of Enterococcus faecalis mediates adhesion to cultured renal tubular cells. Infect Immun 60, 25-30.

Lowe, A. M., Lambert, P. A. \& Smith, A. W. (1995). Cloning of an Enterococcus faecalis endocarditis antigen: homology with adhesins from some oral streptococci. Infect Immun 63, 703-706.

Nallapareddy, S. R., Qin, X., Weinstock, G. M., Hook, M. \& Murray, B. E. (2000). Enterococcus faecalis adhesin, ace, mediates attachment to extracellular matrix proteins collagen type IV and laminin as well as collagen type I. Infect Immun 68, 5218-5224.

Satake, S., Clark, N., Rimland, D., Nolte, F. S. \& Tenover, F. C. (1997). Detection of vancomycin-resistant enterococci in fecal samples by PCR. J Clin Microbiol 35, 2325-2330.

Schlievert, P. M., Gahr, P. J., Assimacopoulos, A. P., Dinges, M. M., Stoehr, J. A., Harmala, J. W., Hirt, H. \& Dunny, G. M. (1998). Aggregation and binding substances enhance pathogenicity in rabbit models of Enterococcus faecalis endocarditis. Infect Immun 66, 218-223.

Sechi, L. A., Zanetti, S., Dupre, I., Cappiello, M. G., Delogu, G., Mortensen, J. E., Daneo-Moore, L. \& Fadda, G. (1998a). Molecular epidemiology by ribotyping and PCR-ribotyping of Enterococcus faecium strains isolated from intercontinental areas. New Microbiol 21, 113-122.

Sechi, L. A., Franklin, R., Dupre, I., Zanetti, S., Fadda, G. \& DaneoMoore, L. (1998b). Characterization of new insertion-like sequences of Enterococcus hirae and their dissemination among clinical Enterococcus faecium isolates. FEMS Microbiol Lett 161, 165-172.

Shankar, V., Baghdayan, A. S., Huycke, M. M., Lindahl, G. \& Gilmore, M. S. (1999). Infection-derived Enterococcus faecalis strains are enriched in esp, a gene encoding a novel surface protein. Infect Immun 67, 193-200.

Shankar, N., Lockatell, C. V., Baghdayan, A. S., Drachenberg, C., Gilmore, M. S. \& Johnson, D. E. (2001). Role of Enterococcus faecalis surface protein Esp in the pathogenesis of ascending urinary tract infection. Infect Immun 69, 4366-4372.

Singh, K. V., Coque, T. M., Weinstock, G. M. \& Murray, B. E. (1998). In 
vivo testing of an Enterococcus faecalis efaA mutant and use of efaA homologs for species identification. FEMS Immunol Med Microbiol 21, 323-331.

Su, Y. A., Sulavik, M. C., He, P., Makinen, K. K., Makinen, P. L., Fiedler, S., Wirth, R. \& Clewell, D. B. (1991). Nucleotide sequence of the gelatinase gene (gelE) from Enterococcus faecalis subsp. liquefaciens. Infect Immun 59, 415-420.

Sußmuth, S. D., Muscholl-Silberhorn, A., Wirth, R., Susa, M., Marre, R. \& Rozdzinski, E. (2000). Aggregation substance promotes adherence, phagocytosis, and intracellular survival of Enterococcus faecalis within human macrophages and suppresses respiratory burst. Infect Immun $\mathbf{6 8}$, 4900-4906.

Toledo-Arana, A., Valle, J., Solano, C. \& 7 other authors (2001). The enterococcal surface protein, Esp, is involved in Enterococcus faecalis biofilm formation. Appl Environ Microbiol 67, 4538-4545.
Wells, C. L., Moore, E. A., Hoag, J. A., Hirt, H., Dunny, G. M. \& Erlandsen, S. L. (2000). Inducible expression of Enterococcus faecalis aggregation substance surface protein facilitates bacterial internalization by cultured enterocytes. Infect Immun 68, 7190-7194.

Willems, R. J., Homan, W., Top, J. \& 9 other authors (2001). Variant esp gene as a marker of a distinct genetic lineage of vancomycin-resistant Enterococcus faecium spreading in hospitals. Lancet 357, $853-855$.

Woodford, N., Soltani, M. \& Hardy, K. J. (2001). Frequency of esp in Enterococcus faecium isolates. Lancet 358, 584.

Zanetti, S., Sechi, L., Angioi, A., Perazzona, B. \& Fadda, G. (1992). Entry of pyelonephritogenic Escherichia coli into HEp-2 cells due to actin polymerization. Microbiologica 15, 117-123. 